\title{
'You taught me language; and my profit on't/Is, I know how to curse': cursing and swearing in foreign language learning
}

\author{
Geraldine Horan* \\ Department of German, School of European Languages, Culture and Society, University College \\ London, Gower Street, London WCIE 6BT, UK
}

This article will discuss why cursing and swearing, as manifestations of emotional language, should be addressed in foreign language learning (FLL). Psycholinguistic and pragmatic studies have argued that cursing and swearing are a central component of an individual's communicative repertoire, fulfilling a variety of functions, including expressions of surprise, joy, frustration, anger and pain. Sociolinguistic studies not only confirm this but also highlight the taboo nature of these utterances, as well as the complex social and group constraints that dictate their usage. Given the central yet controversial status of cursing and swearing, it is hardly surprising that it is largely ignored in FLL, although strong arguments have been advanced in favour of teaching emotional language, which incorporates swearing. This paper will explore the possibilities for making cursing and swearing part of a foreign language curriculum, particularly for advanced learners, and will assess the role currently played by teaching materials. Given the marginalised function of cursing and swearing, and questions of interlanguage synonymy and equivalences, should the acquisition and understanding of cursing and swearing remain outside formal language learning, or do learners need to be made aware of the possibilities for emotional expression, making appropriate use of vulgar and taboo registers?

In diesem Artikel wird diskutiert, warum Fluchen und Schimpfen, als Beispele emotionaler Sprache, im Fremdsprachenlernen behandelt werden sollten. Psycholinguistische und pragmatische Studien behaupten, Fluchen und Schimpfen seien ein wichtiger Teil unseres kommunikativen Repertoires und habe deshalb verschiedene Ausdrucksfunktionen, wie Überraschung, Frust, Wut und Schmerzen, zum Beispiel. Diese Merkmale werden auch in soziolinguistischen Studien identifiziert, allerdings wird hinzugefügt, dass Schimpfen und Fluchen häufig als tabooisiert, bedrohlich und gefährlich betrachtet werden und deshalb als Äußerungen stark verpönt oder sogar verboten werden. Gerade wegen dieses zentralen aber wohl auch kontroversen Status von Schimpfen und Fluchen werden diese tabooisierten Äußerungen im Fremdsprachenunterricht großteils ignoriert, obwohl Forscher in den Bereichen Vielsprachigkeit und interkulturelle Kommunikation das Vermitteln von emotionaler Sprache (auch Schimpfen und Fluchen) für Fremdsprachenlernerlnnen ausdrücklich befürworten. Am Beispiel von Englisch und Deutsch wird dieser Artikel die Gründe und die Möglichkeiten erläutern, weshalb Schimpfen und Fluchen im Fremdsprachenunterricht zumindest thematisiert werden sollten, damit Lernende ihre emotionales Repertoire in der Fremdsprache bereichern können.

Keywords: cursing; swearing; taboo; vulgarism; emotional language; linguistic violence

*Email: g.horan@ucl.ac.uk 


\section{Introduction}

The quotation in the title is taken from Shakespeare's (2011) The Tempest, in which Caliban accuses Prospero of maltreating him. When Prospero claims that Caliban was incapable of speaking any recognisable language before Prospero taught him and civilised him, Caliban retorts 'You taught me language; and my profit on't/Is, I know how to curse./The red plague rid you/For learning me your language!' (I.ii. 366-368). Caliban's response is not only an accusation but also an act of linguistic rebellion: he uses the power of speech he has acquired to curse and therefore rebel against Propero's tyranny. The purpose of highlighting this quotation is neither to engage in literary criticism, for which I am ill-equipped as a linguist, nor to cast language learners in the role of Caliban, but rather to initiate a discussion of the functions of cursing and swearing in a language, and whether language learners should be encouraged in the classroom to acquire these taboo utterances. Although the expression 'communicative competence' (Hymes, 1972) is now rather a cliché in foreign language learning (FLL), in the context of linguistic 'Romanticism' and 'romanticising' language learning, as thematised in this volume, it can usefully refer to the need for foreign language (FL) learners to acquire a repertoire of emotional language that can communicate not only ideas and information but also attitudes and feelings. Although cursing and swearing are by no means the only way to express emotions, they nonetheless represent powerful manifestations of emotional language; they may be 'dangerous', in the sense of being transgressive and potentially facethreatening. In addition to communicating powerful emotions using 'dangerous' language, cursing and swearing can be communicative in another, related sense; these forms of taboo language often express personality, identity, as well as humour, and should, therefore, feature in FLL.

Studies on multilingualism and language acquisition have pointed out that taboo language is rarely included as part of the FL curriculum (Dewaele, 2004), and some have called for the subject to be incorporated into language learning (Jay, 1992; Mercury, 1995), given that cursing and/or swearing, as manifestations of taboo language, are an important part of our communicative repertoire as speakers of a language. Parallel to this discussion, however, is the prevailing attitude in many cultures that cursing and swearing are linguistically impoverished and even morally repugnant utterances, and should, therefore, be avoided at all costs. This faces the FL teacher (and, to some extent, the learner) with contradictory messages regarding the appropriateness of cursing and swearing; yet, I would argue - and aim to illustrate in this article - that these apparent difficulties are not insurmountable within the language learning environment.

In this article, I would like to consider why cursing and swearing should be addressed in language learning and its current presence in language learning materials. There are examples of curse or swear words and expressions being addressed in a particular language in FLL materials; however, this is not a particularly widespread phenomenon. Given that the cursing and swearing play an important role in communicating emotions and attitudes and can be found not only in casual spoken utterances, but also in song lyrics, literature and theatre, their absence from FLL would seem to constitute a glaring omission. The analysis will begin with an outline of definitions and characteristics of cursing and swearing, followed by a discussion of popular attitudes to cursing and swearing before moving on to the question of whether it is desirable or possible to teach or to learn them. I 
am approaching this topic primarily from a sociolinguistic and secondarily from a language pedagogical perspective: like many academics and teachers in tertiary education in the UK, I teach language to students with advanced FL skills, and have acquired experience through teaching rather than through any formal FL or second language teacher (SL) training. My research on the subject so far has examined changing social attitudes to cursing and swearing in German since the sixteenth century, and also the function of dialect swearing dictionaries in German (Horan, 2007, pp. 39-68, 2011, pp. 14-39). What I aim to do is to establish a connection between this historical and contemporary sociolinguistic perspective and the question of communicative competence in second, or third language acquisition and to address the question of whether a speaker of a language can ever hope to be a successful communicator if she/he has not acquired a range of registers and modes of speech, including emotional speech, and therefore swear words. As English and German are the languages in which I have some degree of fluency and can swear with moderate-to-advanced proficiency, my examples will be taken from these two languages.

\section{Cursing and swearing: definitions}

In many respects, the problem begins here: how do we define cursing and swearing? Are there differences between the two? Do we need to have clear-cut definitions in order to teach cursing and swearing? Should cursing or swearing be regarded as discrete forms of the language, or should they be incorporated into a more general understanding of 'taboo' language, vulgarisms, obscenity or profanity? Regarding the way in which curse or swear words are used in context, should we distinguish between utterances such as 'I can't find my fucking keys' and 'fuck off and leave me alone!'? Whereas in the former, the expletive is used as an intensifier, in the latter it is directed at a third person and therefore constitutes an act of verbal aggression. What is clear from just these two examples from English is that any attempt to address the subject of cursing and swearing in language teaching would need to establish some sort of working definition of the terms and a useful categorisation of different types of taboo, vulgar and offensive speech.

'Cursing' is generally defined as an expression which can be in the form of a ritualised formula directed at the addressee, as in 'May you die of a wasting disease' or 'I hope you ...', or through invocation of a divine being, as in 'May God forgive you', as these examples from English demonstrate. Curses can be addressed to the self, as in 'May God strike me dead...', or may explicitly mention the word 'curse' (prevalent in Irish English curses), such as 'The curse of hell on you'. A curse without explicit invocation is also possible, for example, 'Oh hell!' (Horan, 2007, pp. 46-48). These utterances, also referred to as 'profanity', are regarded in Christian faiths as blasphemous, as they call for divine intervention, often flippantly and improperly (Battistella, 2005, p. 72).

'Swearing' is related to 'cursing', in that it calls on divine witness to swearing an oath, and was therefore orginally a religious invocation. However, swearing in a modern context 'refers to something that is taboo and/or stigmatised in the culture; should not be interpreted literally; and can be used to express strong emotions and attitudes' (Andersson \& Trudgill, 1990, p. 53). It is these 'strong emotions and attitudes' that language learners need to know how to express, and this involves an awareness of the lexical fields from which swear words are drawn, as well as an 
understanding of the severity of the expressions used. Swear words are taboo words usually taken from the lexical fields of animals, sex, bodily excretions and disease, and are uttered with force and directed at the self or another. Both curses and swear words 'fulfil a variety of functions, including expletive, abusive, humorous, and auxiliary [i.e. with no specific reference, e.g. in English, 'this bloody car won't work' (Andersson \& Trudgill, 1990, p. 61)], and as such can be regarded as marking emotion in language. It is worth noting that while British English tends to maintain the distinction between 'cursing' in the sense of 'profanity' and 'swearing' in the sense of vulgarity or obscenity, American English uses 'cursing' (or 'cussing') to refer to religious curses and swear words, including the f- and the c-words, for example. For the purposes of this article, I shall refer to 'cursing' and 'swearing' as separate but interrelated utterances. ${ }^{1}$

As social beings, we often express our own emotions or convey the emotions of others in daily interaction, and the categories of cursing and swearing above play an important role in emotional language. Therefore, it is safe to say that whether a language learner chooses to swear, or even avoids swearing, she or he should at least be aware of the patterns, contexts and repercussions of swearing.

\section{Attitudes to cursing and swearing}

To return to Caliban's words quoted above, he learns a language and uses it for 'base' curses. This is not all he can do with language, but it highlights the belief that speaking should be regarded as a privilege, a divine gift that sets humans apart from - and above - other animals. Speech is often imbued with sacredness, as seen through prayer, incantations and ceremonial language of all kinds. Cursing and swearing were, until the previous century, regarded as potentially supernatural utterances, and transgression through the invocation of divine power was regarded as blasphemous and morally reprehensible (Horan, 2007, pp. 47-48). Cursing is still subject to religious censorship, while swearing (i.e. use of expletives) is regarded as 'bad' language, in a combination of language purist and moral judgement. Drawing on metaphors of dirt and disease, swearing is regarded as contaminatory, something that soils the mouth as well as the mind, partly to do with the fact that many swear words are references to bodily functions, for example excretion or sexual activity. In English, this is communicated in admonishing expressions such as 'to wash your mouth out (with soap)', 'potty mouth', and 'you kiss your mother with that mouth?' Swearing is usually excluded from polite usage in many languages, and swear words used in 'inappropriate' contexts, for example, in a court of law, in church, at school, are met with punishment, censure and/or admonition. Attempts to restrict or wipe out cursing and swearing, with at times severe punishment, have been in place in many cultures for centuries. In English and German, for example, pamphlets from the sixteenth and seventeenth centuries decry the current fashion for cursing, and issue dire divine threats to be visited upon cursers and blasphemers, as well as legal consequences including fines and corporal punishments. Such pamphlets, although intended to frighten the language violator into refraining from cursing, serve to illustrate how widespread and commonplace cursing and swearing were (Horan, 2007, pp. 60-62).

In modern times, organisations or movements have been set up with the aim of reducing cursing and swearing, such as the Bond tegen vloeken in the Netherlands and the Cuss Control Academy in the USA. In his book Cuss Control. The Complete 
Book on How to Curb Your Cursing, James V. O'Connor, founder of the Cuss Control Academy states:

Swearing isn't a big crime or a capital sin, but if you control your emotions and focus on being more civil, you will be able to mind your mouth manners or at least reduce your use of verbal vomit. You will achieve greater peace of mind, be a more pleasant person and sound more intelligent. (2000, p. 229)

In this quotation, using the vivid yet inappropriate metaphor of swearing being akin to vomit, O'Connor brings together popular notions of swearing being uncivil and contaminatory, and a sign of low intelligence. The metaphor used is inappropriate in that vomiting is usually seen as a means by which the body purges itself of contaminants. Although the notion of swearing as a form of verbal and emotional release is prevalent [see, e.g., in the German phrase 'Schimpfen ist der Stuhlgang der Seele' ('Swearing is the bowel movement of the soul')], O'Connor portrays swearing as a bad habit; something that cannot be feasibly said of vomiting. Throughout O'Connor's book swearing is portrayed as an addiction, similar to addictions to alcohol, drugs and gambling: a habit that with effort and training, can be broken. Thus, swearing becomes equated with other social vices. Swearing as a sign of low intelligence, a theme that O'Connor pursues throughout the book, is also common in general folklinguistic attitudes to language, and is stigmatised together with other 'non-standard' forms of language including dialect, slang and youth language (Andersson \& Trudgill, 1990; Battistella, 2005). It is often portrayed as 'lazy' and characteristic of the lower classes (Burnham, 1993, p. 208).

Coexistent with the notion of sacred speech is the hierarchy of entitlement and access to certain forms of speech: some are empowered to speak, while others prohibited from doing so. Those who occupy positions of power and use language in an authoritative context have the most to lose but also to gain in using taboo language. The strategic use of cursing or swearing can enhance a speaker's image as being 'downto-earth' or 'one of the people'. It also reinforces traditional notions of masculinity if the speaker is a man, and/or if the speaker is from a higher socio-economic class, cursing or swearing consitutes a minor act of rebellion within the establishment (Battistella, 2005, p. 77). With these popular attitudes in mind, the following represents a discussion of the motivations for making cursing and swearing part of the FL curriculum, as well as a consideration of the problems and challenges involved.

\section{Why should we teach cursing and swearing?}

Teachers and researchers of FL have over many years identified the lack of reference to cursing and swearing in formal education, and debated its possible role in FLL (Dewaele, 2004, 2010; Horan, 2011; Mercury, 1995; Mugford, 2008; Yorio, 1980), which is highlighted by its recurring presence as a topic on various Internet discussion forums. For example, contributors to http://www.how-to-learn-anylanguage.com/forum profanity and swearing debate the necessity to know swear or 'cuss' words in languages other than the native tongue, the effect of swearing on one's own native language in another country, and how the English f-word has been borrowed into a range of languages, including Russian and Icelandic; while http:// www.chromlea.com provides lists of words in various languages sorted according to categories including 'Swear Words, Insults and Bad Language', with glosses in 
English. The website http://www.blogs.transparent.com, which provides access to language and culture blogs in different languages, features a discussion on swear words in the individual languages (e.g., http://blogs.transparent.com/dutch/dutchswear-words/). What is interesting about these discussions is that they are hedged in a humorous, apologetic way: 'What is one of the things many people learn first when they learn a new language? Go on, you can say it - we won't blush. As much as language programs seem to always start with numbers, greetings or even colours, for many people the first word is a swear word' (http://blogs.transparent.com/dutch/ dutch-swear-words/). The website http://www.16kinds.com provides amongst other language information a quick guide to swearing in FL (http://www.16kinds.com/ 2011/11/15/taboo-101-a-five-minute-guide-to-swearing-in-any-language/). This page advises potential swearers to map swear words in their native language onto those they wish to use in the FL, and to be wary of using swear words that they would not consider using in their native language: 'For a learner, then, the taboo word issue must begin with a serious question: what kind of swear-words do you use in your own language? When and how often do you curse?'

These discussions show that some teachers and learners feel that this is an area that has been ignored in FLL, and that this gap should be filled. Discourses on cursing and swearing chime with those that emphasise the need for authenticity in language learning. One could deduce from these discussions that the 'sanctuary of the classroom', Rösler (2000) precludes the acquisition of 'natural language', including cursing and swearing.

\section{Because cursing and swearing are important characteristics of emotional speech}

In the conclusion to Cursing in America, Timothy Jay states 'There is plenty of research yet to be done on the topic of dirty words .... To ignore it is to be ignorant of the totality of human expression' (Jay, 1992, p. 244). This could very easily be applied to FLL: why shouldn't language learners be made aware of the range of registers and expressions available in a language for expressing the gamut of human emotions. In general-purpose as well as academic language learning (i.e. in secondary, primary and tertiary education), considerable emphasis is placed on learning to interact and express oneself using a polite style. In his analysis of teaching impoliteness to SL learners, Gerrard Mugford claims that 'English language teaching tends to deal with the pleasanter side of SL interraction such as making friends, relating experiences, and expressing likes/dislikes while ignoring everyday communicative realities as rudeness, disrespect, and impoliteness' (Mugford, 2008, p. 375). In Mugford's study, he argues that the FL teacher should equip SL learners with knowledge of what kinds of language are considered impolite, what he terms 'declarative knowledge', and/or some understanding of which types of interaction, contexts and practices would require impolite speech, as part of 'procedural knowledge' (Mugford, 2008, p. 382). I would argue that language learners require a combination of both types of knowledge: if we claim that FL users should be able to recognise, react to or even use impoliteness strategies, then it is not enough for them to have a lexicon of appropriate words or expressions without knowing when they would be applied most appropriately, and the reverse is also the case. Although there are many ways in which impoliteness can be expressed, through choice of expression as well as tone of voice, facial expression and gesture for example, at the more extreme end of the impoliteness scale, are cursing and swearing. As it is likely 
that all language learners will encounter cursing and swearing either in spoken interaction, through consumption of the mainstream and new media, or in the written word, it is important that they be alert not only to the vocabulary itself but also to the stylistic and social ramifications of these taboo utterances. While we tend to focus on cursing and swearing as a means of expressing anger, frustration and pain, they can also be employed to communicate surprise, happiness, humour and, in some contexts, familiarity and intimacy. Research by Jean-Marc Dewaele on swearing and multilingualism suggests that without a knowledge of swearing, a nonnative speaker's language might be perceived as 'bland', and the non-native speakers themselves often feel frustrated that they cannot express themselves as forcefully as they would in their native language(s) (Dewaele, 2004, p. 205).

\section{Because language learners are often interested in 'rude' or 'dangerous' language}

There exists the cliché that native and non-native speakers alike share a ludic delight in learning taboo language; anything that is seen as 'rude' or 'dangerous' is immediately of interest. Jay argues that cursing and swearing are of interest to language learners, but are also in their best interest to learn:

[s]ome of the first words that non-native speakers want to know when learning a foreign language are the taboo, dirty, and obscene words in the language. Why is this so? Nonnative $[s i c]$ speakers have to recognize insulting speech directed towards them, as well as know what words not to say in polite situations. $(2000 \text {, pp. } 154-55)^{2}$

Jay's claim about non-native speakers' interest in 'rude' words can certainly be substantiated by the large number of publications on how to swear in FL, with a humorous tone and presentation; for example, Daniel Chaffey's Dirty German: Everyday Slang from What's Up? to $F^{*}$ ck off! (Chaffey, 2008). There are similar publications in this series in Chinese, French, Italian and Spanish. These publications are intended to be light-hearted and humorous and do not have any formal educational aims; as such, they do not contextualise cursing and swearing in the cultures in which the language is spoken and rarely highlight possible differences within one language (e.g. between USA and UK English, or between Austrian German and German German, or between dialect/regionalisms and the standard language). It strikes me that a speaker's interest in taboo words, including those in a FL, and her or his consumption of popular publications on swearing can be harnessed to initiate a discussion of curse and swear words in the classroom (Mercury, 1995, pp. 31-32; Oliver, 2011, pp. 16-19, 21).

\section{Because curse and swear words are versatile and culturally specific}

Contrary to language purist beliefs about the link between taboo language, indolence and contamination, curses and swear words are often rather versatile and creative. The f-word in English is not only very productive within English itself, it has also proved to be a much-borrowed expression into other languages. Andersson and Trudgill describe it as 'one of the most interesting and colourful words in the English language today' (1990, p. 60). It can function as a verb (she fucked with the wrong people), a participle (He is well and truly fucked), a command (Oh, fuck off!), an adjective (That fucking car is playing up again) or an intensifier (fucking awful); and is 
used as a lexical component in compounds such as motherfucker or motherfucking and as an infix in expressions such as hallefuckinglujah! ${ }^{3}$ In addition to being lexically versatile, the f-word can be used strategically in written as well as spoken use, determined by domain of use, as well as class, level of education, age and gender of the speaker (McEnery \& Xiao, 2004). Cursing and swearing tend to be predominantly associated with informal spoken usage, vulgarity and even low culture, yet it is present in the media and traditional forms of 'high culture', including, literature and drama. Shakespeare's use of vulgarisms and insults constitute a form of verbal duelling and is a source of puns, wordplay and low comedy, for example, in Romeo and Juliet and Hamlet. In German, the phrase 'er kann mich im Arsche lecken!' ('he can kiss my arse') in Goethe's Götz von Berlichingen is infamous, and has been the cause of much sniggering amongst generations of school pupils studying the text. An appreciation of US counterculture literature and poetry in the 1950s and 1960s would not be fully possible without taking into account their deconstruction of the formal 'high-brow' literary genre, and the use of taboo language as a form of rebellion and attempt to mimic the alienation and frustration of the post-war generation. Therefore, although it is important to address cursing and swearing as part of everyday spoken emotional utterances, even vulgarisms, one should not neglect the cultural and literary value of taboo language.

\section{Because non-native speakers should be taught how to swear 'properly'}

As well as expanding a learner's communicative repertoire in terms of vocabulary, it is also important to alert them to context, appropriateness and degrees of taboo. A non-native speaker using a particularly strong swear word may not necessarily be aware of its impact or sensitive to just how offensive it is on a scale of taboo words, 'the verbal equivalent of nitroglycerine' (Dewaele, 2004, p. 204). Indeed, as Dewaele has demonstrated, many multilinguals choose to swear in their second, third, fourth, etc., language, as they feel distanced from its taboo and unencumbered by the connotations and social repercussions of employing it. Conversely, however, some multilinguals experience linguistic and expressive liberation through swearing in a newly acquired language; it enables them to express their emotions by harnessing the kind of taboo expressions they would feel uncomfortable using otherwise (Dewaele, 2010, pp. 129-131).

As mentioned earlier in the article, English swear words have proved so popular that they have been borrowed into other languages and are used by speakers who may not have proficiency in English and therefore not be counted as bi- or multilingual. This presents both an opportunity and a challenge to the learner and teacher. In German, for example, the lexeme 'fuck' has been incorporated into expressive speech, particularly of the younger generation (aged 14-30), is found on social networking sites such as Facebook, or on Twitter, seen through posts such as 'Doch Schule morgen. FUCK SCHOOL!' ('Have to go to school after all. FUCK SCHOOL!') or 'fuck, wie geil!' ('Fuck, how cool!'). It is also heard on primetime television, an example of which was when a weather forecaster on a major German TV channel once described the following day's weather as 'fucking bitter cold'. On the radio, English song lyrics containing the f-word are not dubbed: for example, the version of James Blunt's 'You're Beautiful' containing the unedited lyrics 'She could see from my face that I was fucking high' is played rather than the radio edit version used in the USA and the UK, where 'flying high' is substituted. From these examples, we can ascertain that some German 
speakers have incorporated the f-word into their own lexicon, and that the f-word is not regarded as being particularly offensive. In such cases, we cannot or should not aim to interfere with lexical borrowings from English into another language such as German, even if they offend native speakers. After all, the donor language cannot demand that the words be given back. Nonetheless, the language learning environment would provide an opportunity to alert foreign learners to the potential offensiveness of English swear words that they may use in their native language(s) and may not regard as being particularly strong or harmful.

A powerful argument in favour of making swearing part of FL teaching in English is that many non-native speakers (particularly the younger generation) are exposed to vulgarisms and taboo language through song lyrics, English-language television and new media, which gives many of them the impression that English speakers use taboo language much more than they actually do (Mercury, 1995, pp. 32-36). The argument here would be that some FL speakers use foreign (particularly English) swear words because of their prestige ('coolness'), their apparently prolific appearances, and that this will lead to communicative problems for these speakers. They may not be able to judge when and how to use these expressions and may as a result experience hostility or social rejection in particular situations. Rather than leave the topic to the domain of light-hearted, humorous publications such as swearing dictionaries, which often fail to place swear words in their communicative context, the FL classroom could provide an opportunity for contextualised discussion of appropriateness and register.

It is this awareness of differences and similarities in the field of taboo utterances, and of one's own attitude to swear words that could prove most productive and rewarding in FLL. To keep this a merely hypothetical discussion would be to ignore the fact that there already exist printed and online FL materials that address the theme of cursing and swearing. Stephen Fox's Schnellkurs Englisch für Fortgeschrittene (Intensive English for Advanced Learners), includes an English text that thematises the word 'fuck' (2000, p. 58). The text, adapted from Et cetera, et cetera. Notes of a word-watcher by Lewis Thomas, is prefaced with a question asking learners to think about the words they would and would not use in 'mixed company'. It is interesting here that the emphasis is on polite communication, and makes the stereotypical assumptions that men tend to swear more than women and that women are more likely to be offended than men at the use of swear words. The text itself describes the various meanings of the f-word, and how it still has the power to shock, particularly when seen in print. Follow-on exercises include reading comprehension questions and vocabulary exercises linked to the text but not involving swear words. Although the text and exercises are not intended to 'teach' swearing; indeed the accompanying commentary states that the f-word has now gained popularity in the German language, indicating that this is not an item of vocabulary that needs to be taught to German-language learners of English. What it does succeed in doing is to alert learners to the continuing taboo nature of the word and to encourage some reflection on and comparison with the learners' native language and use of swear words.

As an example of FL material that engages with taboo language in a light-hearted manner, whilst also emphasising the potential dangers of cursing and swearing, the publishing company Hueber has produced cursing and swearing 'pin wheels' in English and German that explore both the humorous and non-humorous aspects of cursing and swearing (http://www.hueber.de). The expressions are divided into 10 'themes': 'At School', 'At Work', 'In a Café or Pub', 'In Traffic', 'At a Public Viewing 
Event' [the loan expression 'Public Viewing' in German refers to public screening of (usually) major sporting events on large screens in public spaces], 'Men [talking] about Women', 'Women about Men', 'To Children', 'About Politics and Authorities' and 'About the Weather'. Swivelling the top wheel through these topics reveals the German and English expressions in two parallel windows. In addition, there are lists of suggested swear words and curses on both sides of the wheel, the version for learners of English has 'Basics for every annoying situation', with distinctions made between British English, for example 'Sod it all!' and American English, 'That sucks', 'Basics for when you want to be left in peace', and a list of animal swear words including 'jack-ass' and 'a silly goose'. By comparison, the wheel for learners of German also has the two 'Basics' categories, but divides the animal swear words into those aimed at men, at women and at both. In addition, it includes a cautionary paragraph which outlines the differences between 'schimpfen', meaning to 'swear' or 'cuss' and 'beschimpfen', which is directed at another, in the sense of 'to swear at' or 'have a go at someone'. The description warns that the user should think carefully before directing some of the suggested swear words at someone in an argument or confrontation, saying 'gerade als Nicht-Muttersprachler will schimpfen gelernt sein!' ('the non-native speaker in particular has to learn how to swear!'). These wheels are obviously intended more for amusement than anything else, not least because many of the phrases in the wheel itself cannot be regarded as cursing or swearing; they belong more in the category of complaining or insulting, as seen in the example 'Richard redet nur heiße Luft!' ('Richard talks a lot of tosh!') in 'Women about Men'. But they do highlight two aspects that are central to this discussion: the first is that cursing and swearing are an integral part of humorous and non-humorous verbal confrontations, and the second is that foreign language learners run the risk of cursing and swearing inappropriately in certain situations.

The BBC online language learning materials for French, German and Italian have also included references to swear words. Aimed primarily at younger language learners, the language-specific websites have a section entitled 'Cool [German] or [Spanish]', in which swear words or, more generally, vulgarisms are listed. On the German website, the section entitled 'Interjections' includes 'Scheiße', glossed as 'Shit! An all-time classic', accompanied by three asterisks to indicate that this is a vulgarism (http://www.bbc.co.uk/languages/german/cool/interjections.shtml). Spanish, by contrast, also has the category of 'interjections' but also includes the further categories: 'swearing', 'sexual swear words' and 'religious terms' (http://www.bbc.co. uk/languages/spanish/cool/sexual_flash.shtml).

A publication that is both amusing and informative in this area is Elizabeth Claire's Dangerous English 2000! In its third edition, Claire's guide addresses a wide range of topics under the umbrella heading of 'dangerous words'. These include religious taboos, taboo and vulgar words for the human body, politically incorrect words, sexual harassment and mispronunciations for non-native speakers of English that may cause embarrassment including 'six' and 'sex', and 'city' and 'shitty', example. In the third edition, Claire describes the shocked response of the first publication of the book received in English as a Second Language (ESL) circles, with some recognising the need for material addressing taboo subjects, while some expressing outrage at the book (1998, p. 196). She devotes a section at the end of the book 'To the Teacher', and makes a strong case for why the book should be used in ESL teaching: 
High-school students need and want the information in Dangerous English 2000! They are entitled to a guide to distinguish between the colorful and the off-color language used around them, as well as to dignified ways to speak about their bodies and its functions. To neglect this area is to let them fend on their own, which can cause them embarrassment and get them into trouble. (1998, p. 197)

Although there is a legitimate reason for 'respectful teaching about dangerous language', Claire goes on to caution against using the text in schools, instead recommending its use in voluntary, evening or adult education classes. Claire's cautions about the risks of using the book provide a link to the next section of this discussion, which explores the potential difficulties of teaching cursing and swearing. ${ }^{4}$

\section{The pedagogical implications of teaching cursing and swearing Cursing and swearing are taboo forms of language and therefore difficult and embarrassing to address}

This may seem rather a petty consideration, given the communicative, inter- and cross-cultural benefits of thematising cursing and swearing in the FLL classroom. In her article on swearing and language learning, Mercury states, 'This article does not deal specifically with any practical concerns such as how to go about teaching the taboo word etiquette' (1995, p. 35). This strikes me as being the crux of the problem that faces language teachers: many would agree that it is a good idea in theory to address or discuss taboo language with language learners, but there is a general lack of materials on how precisely to go about this, other than the examples discussed earlier. As Mercury herself asks, should the topic be teacher- or student-led (1995, p. 35)? In addition, the teacher must consider how she or he can avoid the 'cringe factor' in addressing the topic, or, worst of all, alienating and offending class participants.

\section{There is considerable age-related, gender, regional and ethnic variation in the use of cursing and swearing}

The specific vocabulary of cursing and swearing in a given language can be readily identified for the non-native speaker; what remains problematic is the variation in the use of these words according to speaker-preference and context. In his study of impoliteness, Jonathan Culpeper claims that 'the more offensive the item the more context-spanning it is likely to be' (Culpeper, 2011, p. 142). This is certainly the case in many languages: there are a handful of swear words that are regarded as completely or severely taboo. Yet, Culpeper also points to Andrea MillwoodHargrave's study of speakers' evaluation of swear words that 'found that bastard was more likely to be thought "very severe" in the Midlands and north of England (40\% and $39 \%$, respectively) than in the south $(26 \%)$, and that women were more likely to think it "very severe" than men (43\% and 21\%, respectively)", (Millwood-Hargrave, 2000, p. 11 in Culpeper, 2011, p. 142). Turning to context as well as speakerpreference, Culpeper points to Jay's observations that:

people think it is less appropriate for a dean to swear compared with a student; that it is more appropriate for the dean to swear in the office than anywhere else on campus; and that it is very inappropriate for the student to swear in the Dean's office yet appropriate in the student dorm. (Jay \& Janschewitz, 2008, p. 283 in Culpeper, 2011, p. 142) 
Although it may be possible to identify different levels of taboo for swear words, it is these speaker- and recipient-dependent factors and context that determine appropriateness of use, and that may decide whether swearing is 'successful': these are precisely the factors that may not be transmitted successfully in the classroom.

From informal discussions with students, colleagues and friends, it has become apparent to me that swearing is embedded in our idiolects, and that just as we tend to have our own often haphazard collection of grammar 'rules', 'a codex in the head', so to speak, we also tend to have our own swearing inventory. This consists of our own 'favourite' and most reviled swear words, based on social and regional background, and our own scale of taboos. In a seminar on 'Language, Power and Ideology', I put it to my group of students in their final year of undergraduate study that while the expletive 'fuck' is often regarded as being far more taboo than 'shit', I personally find the word 'shit' in spoken usage far more offensive. As an anecdotal example, I cited the situation in which a German-speaking friend uttered the phrase 'Oh shit, I forgot my pen', which I found mildly shocking. I said that I would have found it much less offensive if she had used the f-word. My perspective was one that was not shared by the majority of participants in the seminar discussion. My explanation was that coming from an Irish English background, where curses and the use of the f-word was quite common amongst some of my relatives, together with its euphemistic equivalent 'feck', it did not seem as strong a taboo word to me as the excretory expletive 'shit'. Personal attitudes to the offensiveness of curse and swear words are often influenced by a range of sociolinguistic factors including gender and age, as well as the individual's personality (Dewaele, 2004, pp. 215-216; Mercury, 1995, pp. 34-35). In a language learning environment where there may be participants of different genders, ages and personalities, this presents a considerable challenge to the teacher.

Research in sociolinguistics and critical discourse analysis has shown that it often not the words or the words alone that determine how an utterance is received, but the speaker, and more specifically, how the addressee interprets the speaker's legitimacy in using particular utterances. In the field of language and gender, studies have demonstrated that even though a woman and a man can use the same words, they may be evaluated less positively if spoken or written by a woman. Without factoring in the (potentially unpredictable) reception of the use of swear words by the language learner, as teachers, we could be setting him or her up for an embarrassing, unsuccessful, if not disastrous encounter.

Questions that arise from this are not restricted to swearing but have wider implications for language teaching and learning: authenticity vs. artificiality; one is not 'taught' to swear in one's native language, so why should this be considered appropriate for FL learners? One can to a certain extent 'teach' politeness strategies, as there is an expectation in many social situations that one will attempt to be polite and respect the recipient's and one's own face to some degree. Impoliteness strategies are often driven by spontaneous emotion and are therefore harder to predict, particularly for the non-native speaker.

\section{Cursing and swearing are manifestations of verbal violence}

Part of the problem of teaching cursing and swearing lies with the various functions that these words and expressions fulfil. As discussed in definitions of cursing and swearing, there is significant overlap between cursing, swearing and insulting. The 
borders between exclamation and expletive, between ingroup and intergroup banter, or humour and violent, offensive speech are fluid. Many swear words or expressions are derogatory to particular groups in society, for example, women, old people, gay people, the disabled, etc.; the question is whether the language teacher should address and demystify them, or make students aware of their taboo and offensive nature, or whether highlighting them gives some legitimacy to their use. I am aware that this argument veers dangerously on the boundary between free speech and censorship, and risks drawing comparisons with other societal problems such as drug-taking and prostitution, but I wish to distinguish between these problems from a moral perspective, and the theme of violent language and hate speech. If we argue on the basis of a 'mild' version of the Sapir-Whorf hypothesis, namely that language has some influence on perceptions of reality, and on the tenets of Critical Discourse Analysis, that language creates and perpetuates dominant ideologies (Fairclough \& Wodak, 1997, pp. 258-259, 275-276), this means that, as language teachers, we should not seek to create, transfer or perpetuate discriminatory ideologies or realities through language, even if done with the best of pedagogical and communicative intentions. Therefore, such swear words should be dealt with discursively within a broader discussion of insults, prejudices and verbal violence.

A far less morally perplexing consideration is that we should be wary of teaching cursing and swearing precisely because they are part of taboo language, and taboo language draws its power from transgressing socially agreed and enforced boundaries of taste and politeness. To teaching cursing and swearing, one could argue, is not only to condone the use of potentially offensive language, but also to demystify it, thus rendering it less than powerful. As Tony Grice (2010) argues in his blog on 'Dirty Words in the Classroom', we should leave the teaching of cursing and swearing to the domain outside of the classroom (http://oupeltglobalblog.com/2010/ 10/06/dirty-words-in-the-language-classroom). Although I am not convinced by this argument, it nonetheless adds a note of caution to the consideration of how and why cursing and swearing should be addressed.

\section{Conclusions: finding a place for cursing and swearing in the FL classroom}

It is true that cursing and swearing are largely universal utterances, but there are nonetheless notable differences between languages, with a greater focus on religion, disease, scatology, parts of the body and sex than others. There is also considerable variation, for example, in speakers' definitions of cursing and swearing; their own tendency to use or avoid swear words or curses, and their reaction to hearing them or even being the recipient of them. These differences can be subject to socio-economic status, gender, age and religious affliation in many cases. Cursing and swearing are also context-dependent and are often determined by the formality and emotional tenor of the interaction. As has been mentioned, cursing and swearing are often associated with emotional speech directed at a third party, and this can often be aggressive and derogatory in nature. It is interesting to note in this respect that in many languages tabooisation is shifting from words denoting sex and bodily excretions to racist, anti-disabled and sexist terminology, and this is something the FL teacher has to bear in mind. Should this deter the teacher from addressing cursing and swearing in the FL classroom? The short answer is 'no', but a note of caution is also necessary here: there is little to be gained from 'teaching swearing' in the rather straightforward sense of devoting a lesson to familiarising students with 
cursing and swearing vocabulary. I am also doubtful whether emotional or 'angry' language can be taught in any meaningful sense, as it is frequently governed by spontaneous reaction to a particular situation.

Cursing and swearing, I would argue, do have a place in the FLL curriculum, but within the larger context of thematising and discussing taboo language, and in particular with advanced learners, at tertiary level, for example. This can be achieved through the kind of exercises highlighted in Claire's Dangerous English, or Fox's Schnellkurs für Englisch; in my own undergraduate German-language seminars, for example, I sometimes introduce a German literary or non-literary text with taboo language to initiate a discussion about registers, aggressive language, group identity as well as humour, where relevant. In addition, classroom discussions should address openly linguistic purist and moral attitudes to 'bad language' in general. To return to Caliban's words from The Tempest, cursing and swearing do not constitute contamination of the civilised, civilising and divine gift of language; rather they represent powerful, transgressive and often creative manifestations of emotional language, and without access to these utterances, the FL learner is deprived of some of the most fundamental, humorous, expressive and 'romantic' modes of communication. Therefore, cursing and swearing are a linguistically, communicatively and culturally significant topic that should be addressed sensitively and knowledgeably in the FL classroom.

\section{Notes}

1. I am aware of the interrelationship between the two types of utterance. In his analysis of 'bad language', Edwin Battistella notes that some expressions may contain elements of profanity (cursing) and vulgarity or obscenity (swearing), for example, 'God fucking dammit' (Battistella, 2005, p. 72).

2. See also Dewaele (2004, p. 205): 'Swear words and taboo words are often the first words learned in a L2; however, they rarely appear in textbooks or in classroom discourse because of their offensive nature'.

3. A recent example of the f-word as an infix was provided by Billie Joe Armstrong, lead singer of the American pop-punk band Green Day. In an expletive-laden outburst on stage at the band's music set having been cut short at the iHeart Music Festival in Las Vegas in September 2012, he exclaimed, 'I've been around since nineteen-eighty-fucking-eight!'

4. See also Christopher M. Fairman's discussion of the legal and constitutional implications of teachers using the f-word in US schools (2009).

\section{Notes on contributor}

Geraldine Horan is Lecturer in German Language and Linguistics at University College London. She is author of Mothers, Warriors, Guardians of the Soul: Female Discourse in National Socialism, 1924-1934 (2003) and co-editor of Landmarks in the History of the German Language (2009). Her research interests lie in sociolinguistics, feminist linguistics, discourse analysis, and political discourse, with a particular focus on the relationship between gender, discourse and nationalism. Recently she has also begun to work on taboo language in German and English, and linguistic strategies of humour.

\section{References}

Andersson, L., \& Trudgill, P. (1990). Bad language. Oxford: Blackwell.

Battistella, E. L. (2005). Bad language. Are some words better than others? Oxford and New York: Oxford University Press. doi:10.1093/acprof:oso/9780195172485.001.0001 
Burnham, J. (1993). Bad habits: Drinking, smoking, taking drugs, gambling, sexual misbehaviour, and swearing in American history. New York: New York University Press.

Chaffey, D. (2008). Dirty German: Everyday slang from what's up? to $F^{*}$ ck off! Berkeley, CA: Ulysses Press.

Claire, E. (1998). Dangerous English 2000! An indispensable guide for language learners and others (3rd ed.). McHenry, IL: Delta.

Culpeper, J. (2011). Impoliteness: Using language to cause offence. Cambridge: Cambridge University Press. doi:10.1017/CBO9780511975752

Dewaele, J.-M. (2004). The emotional force of swearwords and taboo words in the speech of multilinguals. Journal of Multilingual and Multicultural Development, 25(2-3), 204-222. doi:10.1080/01434630408666529

Dewaele, J.-M. (2010). Emotions in multiple languages. Houndmills: Palgrave Macmillan.

Fairclough, N., \& Wodak, R. (1997). Critical discourse analysis. In T. A. van Dijk (Ed.), Discourse as social interaction (pp. 258-284). London, Thousand Oaks, and New Delhi: Sage.

Fairman, C. M. (2009). Word taboo and protecting our first amendment liberties. Naperville, IL: Sphinx Publishing.

Fox, S. (2000). Schnellkurs Englisch für Fortgeschrittene [Intensive English for advanced learners]. Ismaning: Hueber Verlag.

Grice, T. (2010). Dirty words in the language classroom. Oxford: Oxford University Press. Retrieved from http://oupeltglobalblog.com/2010/10/06/dirty-words-in-the-languageclassroom

Horan, G. (2007). (Un)Civilized language: The regulation of cursing and swearing in German through the ages. In M. Fulbrook (Ed.), Uncivilizing processes? Excess and transgression in German society and culture: Perspectives debating with Norbert Elias (pp. 39-68). Amsterdam: Rodopi.

Horan, G. (2011). Aapkatt, Ramfotzn, Zierlabbe. What does the Schimpfwörterbuch tell us about the role of swearing in modern German? German as a Foreign Language, 1, 14-39. Retrieved from http://www.gfl-journal.de/1-2011/Horan.pdf

Hymes, D. (1972). On communicative competence. In J. B. Pride \& J. Holmes (Eds.), Sociolinguistics (pp. 269-285). Harmondsworth: Penguin.

Jay, T. (1992). Cursing in America. A psycholinguistic study of dirty language in the courts, in the movies, in the schoolyards and on the streets. Philadelphia and Amsterdam: John Benjamins.

Jay, T. (2000). Why we curse. A neuro-psycho-social-theory of speech. Philadelphia and Amsterdam: John Benjamins.

McEnery, A., and Xiao, Z. (2004). Swearing in modern British English: The case of fuck in BNC. Language and Literature, 13(3), 235-268. doi:10.1177/0963947004044873

Mercury, R.-E. (1995). Swearing: A 'bad' part of language; a good part of language learning. TESL Canada JournallRevue TESL du Canada, 13(1), 28-36. Retrieved from http://www. teslcanadajournal.ca/index.php/tesl/article/viewFile/659/490

Mugford, G. (2008). How rude! Teaching impoliteness in the second-language classroom. ELT Journal, 62(4), 375-384. doi:10.1093/elt/ccm066

O'Connor, J. V. (2000). Cuss control: The complete book on how to curb your cursing. New York, NY: Three Rivers Press.

Oliver, F. E. (2011). Swearing and how to deal with it in the classroom (Unpublished bachelor's thesis). University of Iceland, Reykjavik, Iceland.

Rösler, D. (2000). Foreign-language learning with the new media: Between the sanctuary of the classroom and the open terrain of natural language acquisition. German as a Foreign Language, 1, 16-31. Retrieved from http://www.gfl-journal.de/1-2000/roesler.pdf

Shakespeare, W. (2011). The Tempest (rev. ed.). (V. M. Vaughan and M. T. Vaughan, Eds.). London and New York: Routledge.

Wiktor, K. (2011, November). Taboo 101: A five minute guide to swearing in any language. Retrieved from http://www.16kinds.com/2011/11/15/taboo-101-a-five-minute-guide-to-swearing-in-any-language/

Yorio, C. A. (1980). Conventionalized language forms and the development of communicative competence. TESOL Quarterly, 14(4), 433-442. doi:10.2307/3586232 